\title{
H.O. Pörtner \\ Climate change and temperature-dependent biogeography: oxygen limitation of thermal tolerance in animals
}

Published online: 29 March 2001

(C) Springer-Verlag 2001

\begin{abstract}
Recent years have shown a rise in mean global temperatures and a shift in the geographical distribution of ectothermic animals. For a cause and effect analysis the present paper discusses those physiological processes limiting thermal tolerance. The lower heat tolerance in metazoa compared with unicellular eukaryotes and bacteria suggests that a complex systemic rather than molecular process is limiting in metazoa. Whole-animal aerobic scope appears as the first process limited at low and high temperatures, linked to the progressively insufficient capacity of circulation and ventilation. Oxygen levels in body fluids may decrease, reflecting excessive oxygen demand at high temperatures or insufficient aerobic capacity of mitochondria at low temperatures. Aerobic scope falls at temperatures beyond the thermal optimum and vanishes at low or high critical temperatures when transition to an anaerobic mitochondrial metabolism occurs. The adjustment of mitochondrial densities on top of parallel molecular or membrane adjustments appears crucial for maintaining aerobic scope and for shifting thermal tolerance. In conclusion, the capacity of oxygen delivery matches full aerobic scope only within the thermal optimum. At temperatures outside this range, only time-limited survival is supported by residual aerobic scope, then anaerobic metabolism and finally molecular protection by heat shock proteins and antioxidative defence. In a cause and effect hierarchy, the progressive increase in oxygen limitation at extreme temperatures may even enhance oxidative and denaturation stress. As a corollary, capacity limitations at a complex level of organisation, the oxygen delivery system, define thermal tolerance limits before molecular functions become disturbed.
\end{abstract}

H.O. Pörtner (

Alfred-Wegener-Institut für Polar- und Meeresforschung,

Ökophysiologie, 27515 Bremerhaven, Germany

e-mail: hpoertner@awi-bremerhaven.de

Tel.: +49-471-48311307, Fax: +49-471-48311149

\section{Thermal tolerance and the complexity of physiological function}

Oscillations in the earth's climate lead to associated fluctuations in the temperature regimes of many marine and terrestrial ecosystems. Temperature-related trends in stocks of fish, e.g. North Sea cod (Dippner 1997; O'Brien et al. 2000) or Pacific salmon (Klyashtorin 1997) illustrate the general fact that ectothermic animal species are adapted to and depend upon maintenance of the characteristic temperature window of their natural environment. In contrast to marine mammals and birds, no ectothermic species is known to occur over the widest temperature ranges possible across latitudes between polar and tropical areas. Accordingly, thermal tolerance windows differ between species depending on the range of environmental temperature. Cold stenotherms, for example, are unable to sustain life functions at higher temperatures. Eurytherms tolerate wider temperature fluctuations and, in temperate zones, are able to dynamically shift tolerance windows between summer and winter temperature regimes. Nonetheless, they still specialise within a characteristic thermal environment. Physiological acclimatisation to temperature correlates with increasing genetic differentiation already visible between populations of the same species throughout a latitudinal or altitudinal cline (Hummel et al. 1997; Dahlhoff and Rank 2000). The reasons for the thermal specialisation of animals, i.e. the factors determining and limiting temperature-related geographical distribution, need to be identified.

The present paper summarises recent developments in a concept that may support such an understanding. Using previous data collected in various groups of predominantly marine water-breathing ectotherms (annelids, sipunculids, bivalves and cephalopods among molluscs, crustaceans and fishes) it aims at the development of a unifying hypothesis of thermal limitation and adaptation, which may explain the thermal limits of geographical distribution.

It is widely held that long-term heat tolerance limits for all metazoa are found around $45-47^{\circ} \mathrm{C}$. Higher 
temperatures experienced by some species, e.g. the "Pompeii worm" $\left(105^{\circ} \mathrm{C}\right.$ at hydrothermal deep sea vents, Desbruyeres et al. 1998), a desert ant $\left(53.6^{\circ} \mathrm{C}\right.$, Wehner et al. 1992) are only tolerated during short-term exposure (see Dahlhoff and Somero 1991 for the "Pompeii worm"). The heat tolerance limits of metazoa are much lower than the thermal limits of bacteria, some of which can thrive in continuously boiling waters. Simple eukaryotes such as fungi or algae grow at temperatures from 55 to $60^{\circ} \mathrm{C}$ and, therefore, also display higher tolerance limits than metazoans (Tansey and Brock 1972).

The question arises at which organisational level (molecular, cellular or organismic) the limits of thermal tolerance are likely to be found. Assuming a similar thermal stability of aerobic heterotrophic metabolism in prokaryotes and eukaryotes, Tansey and Brock (1972) hypothesised that the formation of intracellular organelles such as nuclei and mitochondria in simple eukaryotes might have reduced heat tolerance. Organellar membranes selectively transport macromolecules and, therefore, these membranes may be leakier and less thermostable than plasma membranes. However, this argument does not explain the further reduction in heat tolerance from simple eukaryotes to metazoans. This problem may be solved by considering the formation of organelles as a gain in structural and functional complexity between pro- and eukaryotes. Even higher levels of organisational complexity are added in metazoans, by the specialisation of tissues, the establishment of central control and the requirement to circulate and move body fluids and air or water for homeostatic maintenance and gas exchange. Associated with this gain in complexity is an increase in metabolic rate, reflecting a performance increment between unicellular organisms and animals (Hemmingsen 1960, cited by Schmidt-Nielsen 1997). The rise in performance may occur at the expense of greater thermal sensitivity. The limits of tolerance would then be set at the highest level of organisational complexity, i.e. the functional coordination of cells and tissues towards a larger unit.

For an identification of the mechanisms of thermal limitation and adaptation, it needs to be considered that the crucial mechanism should link low and high tolerance limits, which shift unidirectionally. Changes occurring in the warm should reverse the processes elicited by cold exposure. If individual molecular mechanisms are involved in thermal limits and adaptation, whole-animal limits and the limits of these mechanisms should at least be correlated.

In consequence, thermal limits need to be investigated at both the high end and the low end of the temperature spectrum. Sensitivity levels of molecules, organelles, cells, tissues and the intact organism need to be distinguished as well as the difference between mechanisms responsible for long- and short-term tolerance. This includes the key question as to which physiological processes define the temperature window of growth and reproduction as required for successful long-term maintenance of a population in its natural environment.

\section{Oxygen limitations at pejus and critical temperatures}

In previous years critical temperature thresholds $\left(T_{\mathrm{c}}\right)$ have been defined for various marine invertebrate species and, most recently, for fish as being due to the transition to an anaerobic mode of mitochondrial metabolism. In a marine worm, Sipunculus nudus, this transition occurred below a threshold temperature of $4^{\circ} \mathrm{C}$, associated with progressive hypoxia in the body fluids and finally collapse of ventilatory peristalsis (Zielinski and Pörtner 1996). Sommer et al. (1997) and Frederich and Pörtner (2000) demonstrated for the lugworm, Arenicola marina, and the spider crab, Maja squinado, that anaerobic mitochondrial metabolism not only occurs beyond low but also above high temperature extremes. The characteristics of high critical temperatures were investigated in fish and cephalopods (for review see Pörtner et al. 1998, 2000). In all studies reported (Fig. 1), the onset of mitochondrial anaerobiosis occurs in fully aerated water and indicates a transition to passive, time-limited tolerance. In annelids, cephalopods, bivalves and fish, high critical temperatures were associated with a drastic rise in oxygen demand (Fig. 2).

Critical temperatures differ between species and populations depending on latitude or seasonal temperature acclimatisation and are therefore related to geographical distribution. For example, both low and high $T_{\mathrm{c}}$ values were lower in a cold-adapted, sub-Arctic population of A. marina from the Russian White Sea than in boreal, North Sea specimens (Sommer et al. 1997; Fig. 1). High critical temperatures were found close to $23^{\circ} \mathrm{C}$ and $9^{\circ} \mathrm{C}$ in eelpout from the North Sea and from the Antarctic, respectively (van Dijk et al. 1999; Fig. 1). Even lower long-term "heat tolerance" limits of $2-3{ }^{\circ} \mathrm{C}$ were found in an Antarctic bivalve, Limopsis marionensis (Pörtner et al. 1999a).

The body wall musculature of worms and the mantle musculature of cephalopods not only represent a large fraction of the musculature but are also ventilatory organs actively and continuously involved in oxygen uptake. In these cases, anaerobic glycolysis was observed in addition to mitochondrial anaerobic metabolism (Fig. 1). In S. nudus, a correlated decrease in ventilatory performance and oxygen tension $\left(\mathrm{PO}_{2}\right)$ in coelomic fluid occurred prior to anaerobiosis. In the spider crab, M. squinado, both ventilatory and circulatory performance fell, together with haemolymph $P_{2}$ before critical temperatures were reached. At medium temperatures between 8 and $17^{\circ} \mathrm{C}$, high oxygen levels in the haemolymph suggest a range of optimum oxygen supply to tissues. The transition from a temperature range with maximum arterial $\mathrm{PO}_{2}$ to progressively hypoxic body fluids during both warming and cooling reflects a set of low and high threshold temperatures (called pejus temperatures, $T_{\mathrm{pI}}$ and $T_{\mathrm{pII}}$, pejus means turning worse, deleterious), which are found well within the range encompassed by critical temperatures (Frederich and Pörtner 2000; Fig. 3). The drop in arterial $P_{2}$ reflects a reduction of oxygen availability to mitochondria, which will 


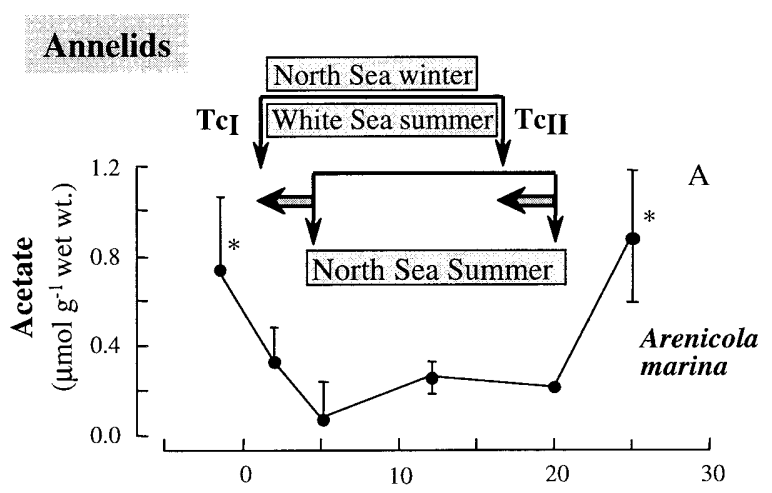

Cephalopods

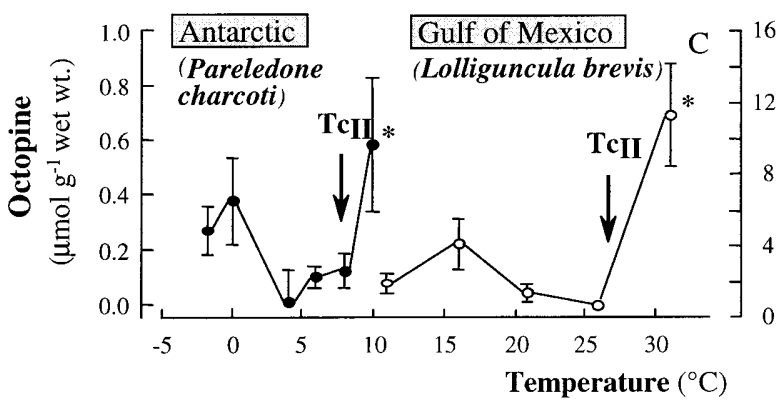

Fig. 1 Increased concentrations of various anaerobic end products formed in tissues of marine invertebrates and fish (body wall and mantle musculature in annelids and cephalopods, respectively). Both $T_{\mathrm{cI}}$ and $T_{\mathrm{cII}}$ vary depending on environmental temperatures at various latitudes and seasons. (modified after Sommer et al. 1997; Pörtner and Zielinski 1998; van Dijk et al. 1999; Frederich and Pörtner 2000)

no longer achieve maximum rates of oxygen consumption. A reduced scope for aerobic activity of the whole animal results. Aerobic scope as defined by measurements of oxygen consumption in fish (Bennett 1978) quantifies the range between minimum and maximum oxygen consumption and extends from the whole animal to tissue to mitochondrial levels (Lindstedt et al. 1998). In conclusion, oxygen limitation at cold or warm temperatures sets in prior to functional failure, which finally develops beyond critical temperatures (Zielinski and Pörtner 1996; Sommer et al. 1997; Sommer and Pörtner 1999; Frederich and Pörtner 2000). Ventilatory failure in cold-exposed $S$. nudus is characterised by critically low cellular energy levels quantified as the Gibbs free energy of ATP hydrolysis (Zielinski and Pörtner 1996).

\section{Capacity-limited ventilation and circulation}

During warming the high haemolymph $\mathrm{PO}_{2}$ between $T_{\mathrm{pI}}$ and $T_{\mathrm{pII}}$ in the spider crab was maintained by increasing heart and ventilation rates as required to compensate for the rise in oxygen demand in the warm. Above the high

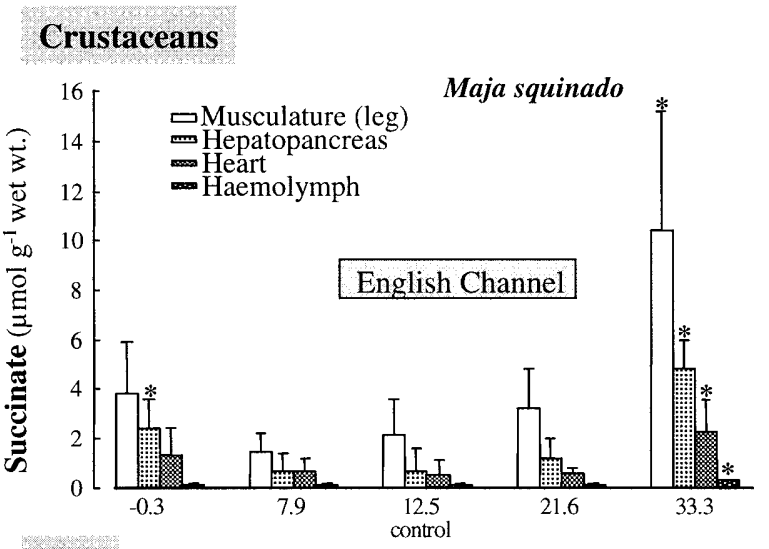

Fish

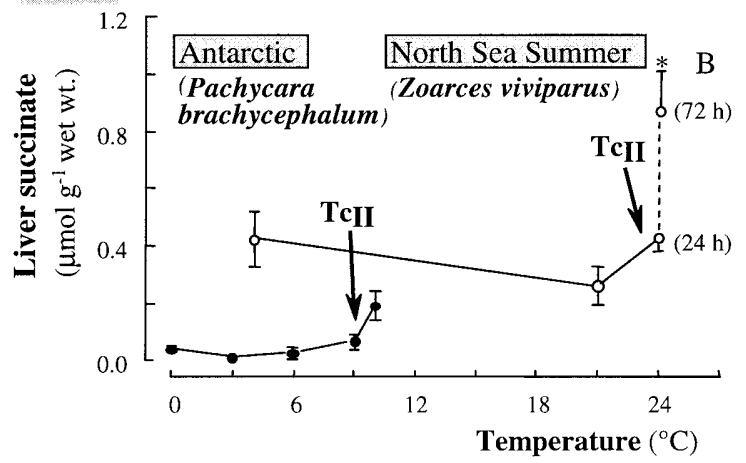

pejus temperature $\left(T_{\mathrm{pII}}\right)$ a decrease in $\mathrm{PO}_{2}$ occurred when ventilation and heart rates became more or less constant and independent of temperature indicating that the rise in oxygen demand was no longer compensated for. Below the low pejus temperature $\left(T_{\mathrm{pI}}\right)$ a further decrease in ventilation and heart rate, followed by a decrease in $\mathrm{PO}_{2}$, also indicated insufficient oxygen uptake and transport (Zielinski and Pörtner 1996; Frederich and Pörtner 2000; Fig. 3). In conclusion, capacity limitations of oxygen uptake and delivery cause oxygen limitation in fully aerated media.

A progressive deviation of ventilation frequency from the normal $Q_{10}$ relationship in the notothenioid fish, Lepidonotothen nudifrons (Hardewig et al. 1999) also indicates capacity-limited ventilation in the warm. In heatstressed Antarctic clams, Laternula elliptica, a decrease in oxygen uptake during long-term recording coincided with a concomitant decline in heart rate (L.S. Peck, I. Hardewig and H.O. Pörtner, unpublished). Studies summarised by Farrell (1997) suggest that in temperate salmonid fish the limits of aerobic scope in the heart may cause insufficient blood circulation at extreme temperatures. This may explain the drop in venous rather than arterial oxygen tensions observed during warming in cod (cf. Pörtner et al. 2000, 2001). Hypoxia and, finally, anaerobic metabolism results at the tissue level, at first in tissues with a high oxygen demand such as vertebrate liver (Fig. 1).

In conclusion, the slowing of ventilation and circulation in the cold and, conversely, the insufficient increase in the warm, cause a mismatch between oxygen delivery 


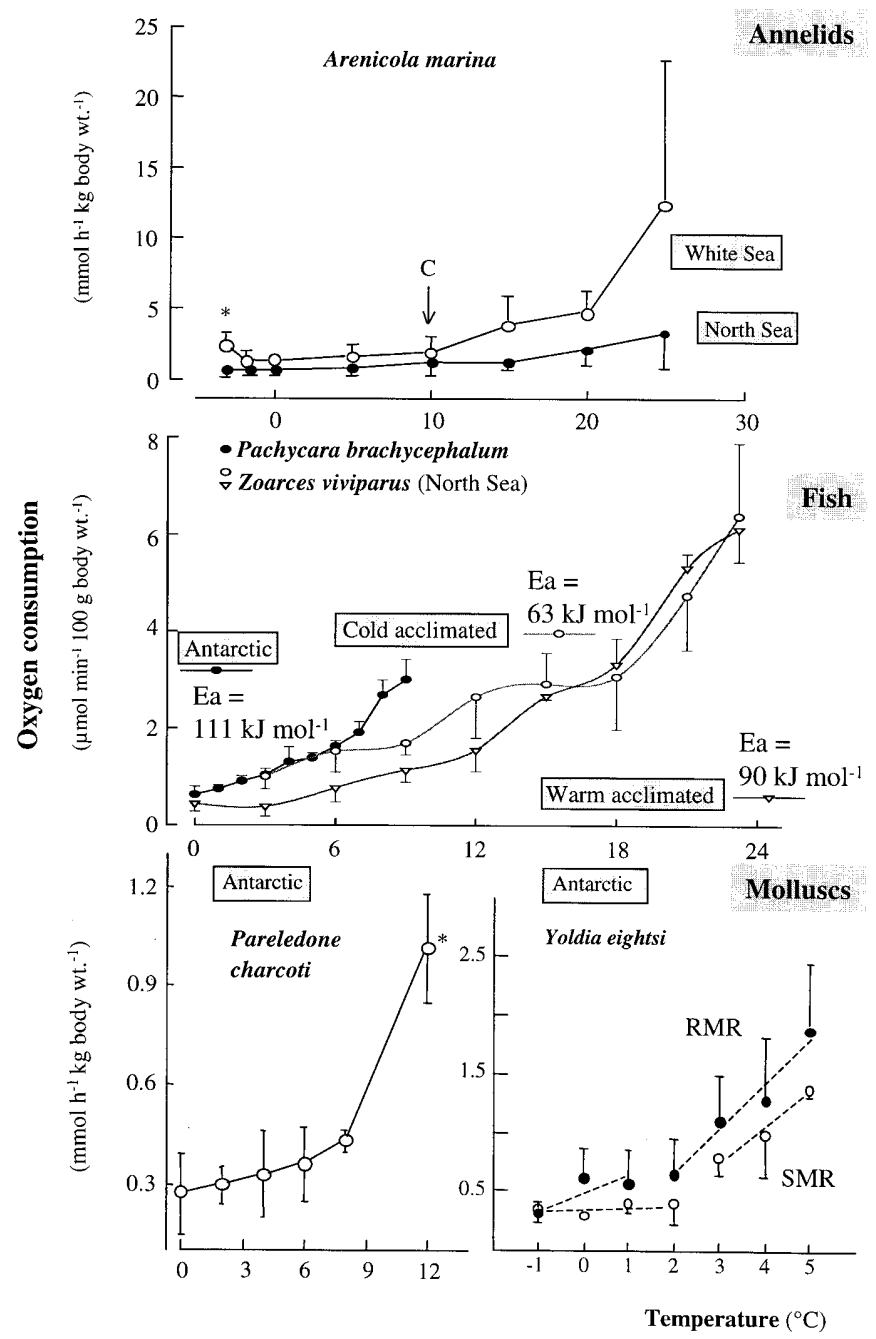

Fig. 2 Temperature-dependent oxygen consumption in various marine invertebrates and fish from temperate and polar areas (modified after van Dijk et al. 1999; Pörtner et al. 2000; Abele et al. 2001; A. Sommer, H.O. Pörtner and T. Hirse, unpublished). Oxygen uptake rises steeply with temperature, especially in coldadapted populations of a eurythermal species (annelids) or in cold stenothermal polar animals (Antarctic fish and molluscs). Thermal sensitivity is identified by high levels of Arrhenius activation energy $\left(E_{\mathrm{a}}\right)$. Note the drop in $E_{\mathrm{a}}$ in eurythermal North Sea eelpout when acclimated to cold compared with warm temperatures in the laboratory

and demand which leads to a drop in aerobic scope, transition to anaerobic metabolism and finally collapse of higher physiological function in fully aerated environments. Insufficient capacity of ventilation or circulation would not only be the cause of the mismatch between oxygen uptake and demand at extreme temperatures but vice versa, ventilatory or circulatory organs may also be the first to experience the sequence of limited aerobic scope, oxygen deficiency, anaerobiosis and energetic failure. Oxygen limitation, limited functional capacity and finally failure most probably go hand in hand. In accordance with the prediction developed above, oxygen uptake and distribution by ventilation and circulation are

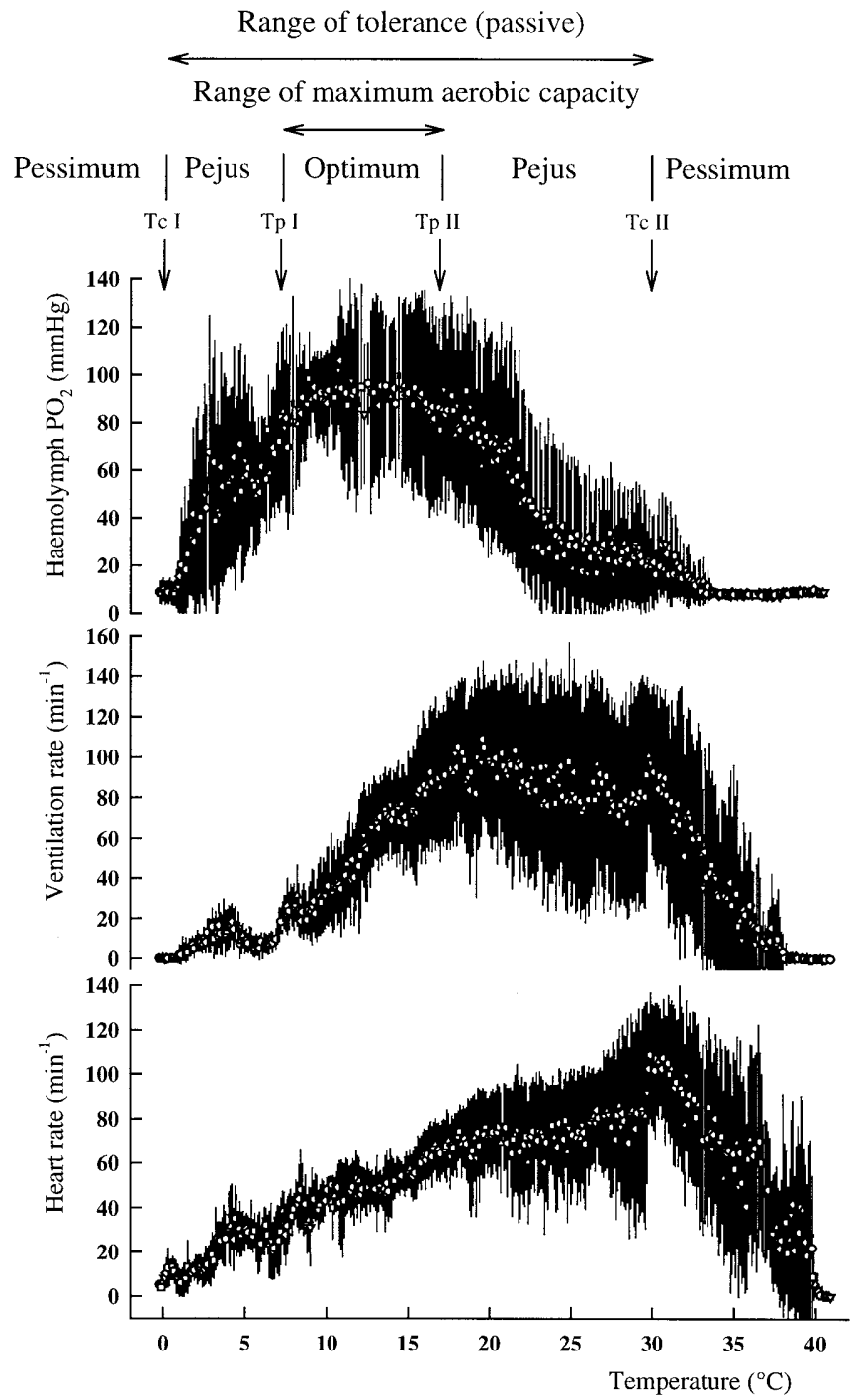

Fig. 3 Correlated changes of haemolymph oxygen tensions $\left(\mathrm{PO}_{2}\right)$ and ventilation and heart rates in the spider crab, Maja squinado, between 0 and $40{ }^{\circ} \mathrm{C}$. The $P_{2}$ profile characterises the level of aerobic energy available to the animals and matches optimum, pejus and pessimum ranges with respect to temperature, as adopted from the law of tolerance (Shelford 1931; Schwerdtfeger1977). Threshold temperatures $\left(T_{\mathrm{cI}}\right.$ and $T_{\mathrm{pI}}, T_{\mathrm{pII}}$ and $\left.T_{\mathrm{cII}}\right)$ are identified by breakpoints in ventilation rate and corresponding changes in $\mathrm{PO}_{2}$ and heart rate (after Frederich and Pörtner 2000)

most likely those processes of a high organisational complexity which set the limits of thermal tolerance.

\section{Ecological and evolutionary implications}

Shelford (1931) defined the law of tolerance, which was used and extended by Schwerdtfeger (1977) to describe the changing performance of organisms within optimum, pejus and pessimum phases of the tolerance range with respect to environmental factors. Frederich and Pörtner (2000) applied the respective terminology to the profile of haemolymph $\mathrm{PO}_{2}$ obtained in M. squinado (Fig. 3). 
Accordingly, the range of maximum $P_{2}$ indicates the temperature range of full aerobic scope and optimum performance of the animal. Within this range, availability of aerobic energy is maximal for all physiological functions including growth and reproduction. Thermal limitation has already set in at the transition from the optimum to pejus range (Fig. 3), characterised by the drop in aerobic scope.

Early work by J.R. Brett demonstrated that in sockeye salmon (Oncorhynchus nerca), activity and even more so reproduction (which includes associated activity) occurs within much narrower thermal windows than metabolic maintenance (for a review see Cossins and Bowler 1987). A sequence of thermal limits results, where oxygen limitation indicates the earliest limits reached, namely the limits of long-term tolerance including growth and reproduction. At temperatures outside this range, tolerance still exists but becomes progressively time limited. This explains why survival thresholds identified by heating or cooling within minutes or hours in fish (cf. Elliott and Elliott 1995) or even in Antarctic invertebrates (Lahdes 1995; Urban 1998) are found to be higher in the warm (lower in the cold) than the limits of long-term thermal tolerance. Mainly the latter are ecologically relevant, whereas the former may be correlated with the latter. For example, the upper lethal temperature $\left(\mathrm{LT}_{50}\right)$ for the Antarctic bivalve, Laternula elliptica, has been determined as $14.9^{\circ} \mathrm{C}$ after $24 \mathrm{~h}$ of acute temperature exposure (Urban 1998). However, oxygen limitation has already set in at a pejus temperature close to $4^{\circ} \mathrm{C}$ (H.O. Pörtner, L.S. Peck and T. Hirse, unpublished). Interestingly, this is very close to the temperature $\left(3.6^{\circ} \mathrm{C}\right)$ at which $50 \%$ of the animals lost the ability to rebury in the sediment (Urban 1998). As a corollary, pejus temperatures probably indicate the limitation of aerobic energy for activity as well as growth and reproduction. Pejus temperatures may therefore be closest to the temperature limits of the geographical distribution of a species (cf. Frederich and Pörtner 2000; Fig. 3).

The width of the window between the two pejus temperatures, as well as between critical temperatures, reflects the capacity of ventilation and circulation and the level of aerobic scope in accordance with the amplitude of temperature fluctuations in the habitat of a species. However, aerobic scope is also defined by motor activity, which is higher in active fish or octopods than in mussels. This may explain the higher critical temperatures in more mobile compared with sessile Antarctic species (Pörtner et al. 2000).

An overview of the thermal tolerance ranges of tropical, temperate and polar bivalves and other ectotherms, compiled from the literature by Peck and Conway (2000), suggests that tolerance windows are wider in tropical and temperate species than in polar stenotherms. With the proviso that many of these data have been determined by using classical protocols, Fig. 4 indicates that adaptation to permanently low temperatures in polar areas leads to a narrowing of the tolerance window. True stenothermality may therefore only exist in the cold. Life in the cold ap-

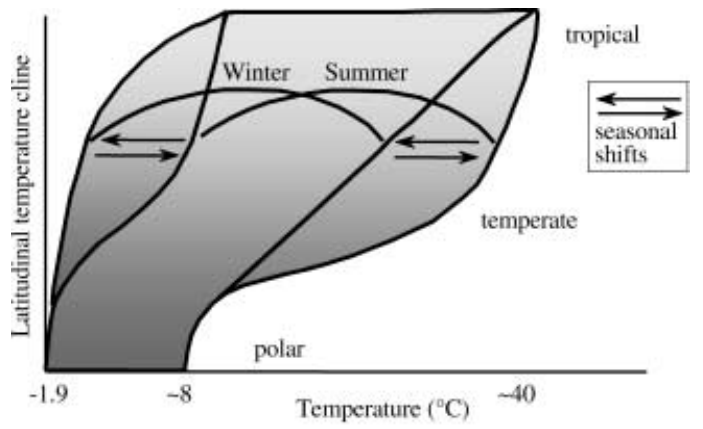

Fig. 4 Thermal tolerance data collected by Peck and Conway (2000) for marine ectotherms from various latitudes (based on classical determinations during short-term heating protocols and on previous determinations of $T_{\text {cII }}$ ) turned into a modelled depiction of cold and heat tolerance in a latitudinal cline. Seasonal shifts of tolerance windows occur in animals from temperate zones. Note that tolerance windows are narrowest in cold stenotherms from polar areas (see text)

pears as a severe challenge, while life in warm waters is more likely to reflect the original evolutionary situation (cf. Arntz et al. 1994). In fact, a drop in winter temperatures by about $4^{\circ} \mathrm{C}$, with sum-mer temperatures remaining constant, may have caused the mass extinctions of marine invertebrates at the Eocene/Oligocene boundary (Ivany et al. 2000). The limited capacity of species to adapt to low temperatures may also explain the decrease in biodiversity of marine invertebrate macrofauna (exemplified by marine prosobranch gastropods) correlated with the drop in average sea surface temperature towards higher (Northern) latitudes. Diversity falls drastically between 30 and $18^{\circ} \mathrm{C}$ (Roy et al. 1998). This drop slows considerably at temperatures below about $18^{\circ} \mathrm{C}$ or above $35^{\circ}$ in Northern latitudes, possibly reflecting successful adaptation to increased seasonal temperature oscillations in the remaining animal species. Also, the amplitude of climate oscillations (so-called Milankovitch climate oscillations), which are driven by periodical changes in the orbit of the Earth, has been higher over the last 300,000 years towards higher, especially Northern, latitudes, thereby favouring survival of eurythermal species with a lower level of specialisation than in the tropics or Southern hemisphere (Dynesius and Jansson 2000).

\section{Thermal tolerance limits in air breathers}

According to the previous section, evidence is strong that thermal tolerance limits in highly organised water breathers are set by limited oxygen supply to tissues. The question arises as to how the transition to air breathing may have changed the sequence of thermal tolerance limits (from loss of aerobic scope to onset of anaerobic metabolism and then molecular denaturation). Breathing air implies a reduction by one order of magnitude in the energy cost of ventilation at about 30 times higher levels of ambient oxygen. This may have allowed air breathers to be more eurythermal than water breathers. This princi- 


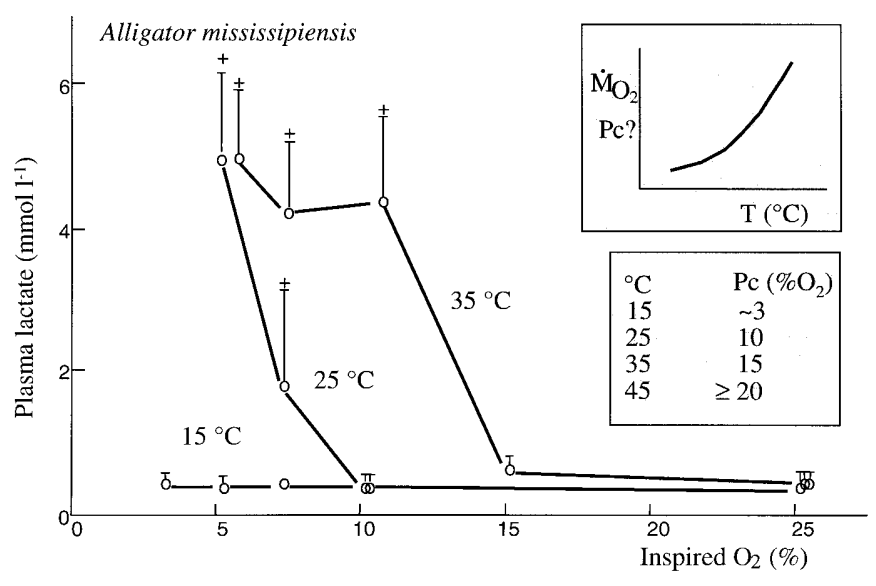

Fig. 5 Temperature dependence of the critical $P_{2}\left(P_{c}\right)$ in the alligator, Alligator mississipiensis (after Branco et al. 1993). Insets depict the temperature-dependent rise in oxygen consumption and $P_{\mathrm{c}}$ associated with the rise in hypoxia sensitivity (top) and the extrapolated temperature at which the $P_{\mathrm{c}}$ reaches normoxic oxygen tensions (bottom). It is presently unclear $\left(P_{\mathrm{c}}\right.$ ?) whether the $P_{\mathrm{c}}$ increases exponentially with temperature

pal advantage compensates for the fact that thermal buffering is minor and temperature fluctuations are larger in the terrestrial compared to the aquatic environment. Nonetheless, specialisation of physiological function to a thermal window is still observed in air breathers, even in mammals and birds, where maintenance of body core temperature occurs either by insulation from the environment or by mechanisms of improved heat transfer.

If long-term heat tolerance limits in metazoa are generally found around $45^{\circ} \mathrm{C}$, highly organised air breathers, for the reason of being more eurythermal, may approach that limit more closely than water breathers. However, the mechanisms limiting heat tolerance have not really been established in air breathers. Oxygen limitation has not been investigated. Vague estimates of the critical temperature are possible for some ectothermic species from warmer climates. In the alligator, Alligator mississipiensis, the critical $\mathrm{PO}_{2}$, i.e. the limiting level of ambient oxygen, identified by the onset of anaerobic metabolism, increases as temperature rises and reaches normoxic values at about $45^{\circ} \mathrm{C}$. Here aerobic scope vanishes in accordance with the above definition of the $T_{\mathrm{c}}$ Branco et al. 1993; Fig. 5). In several freshwater turtles, alveolar oxygen extraction becomes limiting in the warm (e.g. Jackson 1971). $\mathrm{PO}_{2}$ levels in the lung decrease and alveolar, critical $\mathrm{PO}_{2}$ increases at high temperatures (White and Somero 1982; Fuster et al. 1997). Both curves would intersect at a $T_{\mathrm{c}}$ between 40 and $45^{\circ} \mathrm{C}$. In the cold (below $10-15^{\circ} \mathrm{C}$ ) malfunction of the circulatory system was observed in desert scorpions (Bridges et al. 1997). In tarantulas (Eurypelma californicum), exposure to temperatures below $15^{\circ} \mathrm{C}$ leads to acetate accumulation (R.J. Paul, unpublished) indicating anaerobiosis in the cold. In weevils and mountain beetles, cold adaptation of metabolic parameters occurs (Chown et al. 1997; Chown and Gaston 1999; Dahlhoff and Rank 2000), reflecting simi- lar mechanisms to overcome oxygen-limited cold intolerance in terrestrial as in aquatic ectotherms.

According to Addo-Bediako et al. (2000) upper lethal limits in insects (on average $47.4{ }^{\circ} \mathrm{C}$ ) are not correlated with ambient extremes or latitude. Since these limits have been determined during experimental short-term temperature increments, the same precautions apply as for water breathers. In contrast to $T_{\mathrm{c}}$ and $T_{\mathrm{p}}$, short-term tolerance limits beyond upper pejus temperature and, most probably, critical temperatures may not be correlated with geographical distribution, at least not in insects.

Studies of thermal tolerance in endotherms usually focus on the pathology of heat shock and cold injury. This includes the cellular mechanisms of heat or cold hardening by heat shock proteins and related chaperones (e.g. Burdon 1987; Fujita 1999) as well as temperatureinduced injuries by oxygen radical formation (Ando et al. 1994; Bhaumik et al. 1995), endotoxaemia (Caputa et al. 2000) or elevated calcium levels (Ivanov 2000). Progressive circulatory failure below $20^{\circ} \mathrm{C}$ in the rat leads to progressive energy deficiency and elevated lactate levels (Jourdan et al. 1989). Accordingly, functional failure (capacity limitation) of circulation and tissue perfusion would again limit cold tolerance. The role of oxygen demand in heat tolerance is not clear. However, many events discussed for both cold and heat damage are similar to those elicited by hypoxia or ischaemia, including the formation of oxygen radicals (Rifkind et al. 1993; Ivanov 2000).

The situation becomes much clearer for air breathers if it is considered that, as in water breathers, the window delimited by pejus temperatures will be smaller and closer to environmental temperature oscillations than the window defined by critical temperatures. The conclusion arises that the reduction of aerobic scope sets the longterm limits of thermal tolerance in both air and water breathing ectotherms. If oxygen limitation characterises thermal intolerance in general, it is no longer surprising that lactate as an end product of anaerobic metabolism is able to elicit behavioural hypothermia in aquatic and terrestrial ectothermic vertebrates. In vertebrates and some invertebrates, lactate indicates extreme oxygen limitation and, at the high $T_{\mathrm{c}}$, would stimulate the organism to move to cooler temperatures (Pörtner et al. 1994; De Wachter et al. 1997; Branco and Steiner 1999). Optimised functions depending on temperature are supported by behavioural thermoregulation in both ecto- and endotherms, by choosing adequate thermal niches to maximise activity and reactivity or to escape from daily or seasonal temperature extremes by hiding in the shade or underground. In endotherms, behavioural adjustments to the thermal environment include long-range migrations as far as from one pole to the other as in the tern, Sterna paradisaea.

\section{Symmorphosis and thermal optima}

A limiting role of oxygen supply systems becomes understandable when the functional capacity of ventilatory 
and circulatory structures is set to a minimally required level in accordance with metabolic requirements. These considerations are in line with the concept of symmorphosis which has been developed for the mammalian respiratory system (Taylor and Weibel 1981) and which considers the combination of functional elements towards higher levels of integration. This concept states that animals maintain just enough structure to support oxygen flux at maximum oxygen uptake rates. The design of all components of a system match functional demand in a way that excess capacity of any single component is avoided (Hoppeler and Weibel 1998). In the context of thermal adaptation and limitation, this means that the functional capacities of oxygen delivery systems are set to be optimal between the average highs and lows of environmental temperatures.

\section{Shifting tolerance limits during thermal adaptation}

The overall conclusion from these data is that adaptation to extreme temperatures involves escaping the threat of temperature-induced hypoxia (Pörtner et al. 1998, 2000). Temperate zone species, in particular, possess the ability to shift both low and high tolerance thresholds $\left(T_{\mathrm{p}}\right.$ and $T_{\mathrm{c}}$ ) during acclimatisation to changing temperatures (Figs. 1, 4). Baseline constraints and tradeoffs in cold or warm adaptation need to be identified.

Acclimation to seasonal cold causes a rise in mitochondrial density or mitochondrial aerobic capacity (St-Pierre et al. 1998; Guderley 1998). This process is reversed during seasonal warming. High mitochondrial densities have also been observed in polar ectotherms adapted to permanent cold. A wealth of information has been collected in fish (for a review see Guderley 1998) and only recently has cold-induced mitochondrial proliferation been confirmed for a marine invertebrate (A. Sommer and H.O. Pörtner, unpublished). The interpretation that temperature-induced changes in mitochondrial densities and functional capacities are related to a shift in oxygen-limited thermal tolerance windows casts new light on the functional role of these changes.

As outlined above, mitochondrial density and aerobic capacity reflect the level of aerobic scope of the whole animal. Sufficient ventilation and circulation is required to keep $\mathrm{PO}_{2}$ high and to make aerobic scope available. In the cold, the limited capacity of mitochondria to produce energy is likely to contribute to the loss of function and scope, e.g. in circulation and ventilation. This may be the key to understanding why an increase in mitochondrial aerobic capacity occurs during resistance adaptation to cold (Pörtner et al. 1998, 2000) as these processes elicit a downward shift of the low temperature thresholds (critical and pejus).

In the warm, the increase in oxygen demand may become a problem. It has only recently become clear that oxygen demand is not only related to cellular energy requirements, which is met by ATP synthesis in oxidative phosphorylation, but also to the rate of proton leakage across the inner mitochondrial membrane. Mitochondrial proton leakage comprises a constantly large fraction of standard or resting metabolic rate (SMR), 20-30\% in the whole animal, in ectotherms and endotherms (Brand 1990; Brand et al. 1994; cf. Brookes et al. 1998), 25\% in rat hepatocytes, and 50\% in skeletal muscle (Brand et al. 1994; Rolfe and Brand 1996). On top of the cost of biosynthesis and degradation, proton leakage reflects the baseline idling of mitochondria and cost of mitochondrial maintenance (Pörtner et al. 1998). SMR is related, by a more or less constant factor, to aerobic scope of the organism (Wieser 1985; Brand 1990; Lindstedt et al. 1998). Proton leakage will therefore contribute to the temperature-induced increase in SMR. The thermal sensitivity of proton leakage was found to be high in Antarctic bivalves and fish (Pörtner et al. 1999b; Hardewig et al. 1999). Whatever the mechanism of proton leakage, its high thermal sensitivity suggests that the futile cycling of protons may increase to a similar or even larger extent than resting ATP turnover at high temperatures. Thus it might contribute to the exponential rise in oxygen demand (Fig. 2) which is no longer met by oxygen uptake. As a corollary, the reduction of mitochondrial density observed during warming probably leads to a reduction in baseline oxygen demand, thereby allowing the upper $T_{\mathrm{p}}$ and $T_{\mathrm{c}}$ to shift to higher values, leaving enough aerobic energy for ventilation and circulation to maintain aerobic scope.

The key role of mitochondria in setting aerobic scope, including the functional capacity of ventilation and circulation, does not ignore the importance of integrated modifications in lipid saturation, kinetic properties of metabolic enzymes, contractile proteins and transmembrane transporters (cf. Johnston 1990; Hazel 1995; Pörtner et al. 1998; Storelli et al. 1998), all of which will contribute to the optimisation of complex functions within the window of thermal tolerance.

\section{Summary and conclusions: towards a unifying concept}

Figure 6 illustrates the sequence of thermal sensitivities. Oxygen delivery by ventilation and circulation most probably is the systemic process of high organisational complexity that defines the first line of thermal sensitivity at pejus temperatures ( $T_{\mathrm{p}}$ in Fig. 6$)$ owing to capacity limitations. The transition to hypoxia and, finally, an anaerobic mode of mitochondrial metabolism then characterises passive tolerance limits beyond critical temperatures $\left(T_{\mathrm{c}}\right)$. In accordance with the prediction mentioned earlier, the adjustment of mitochondrial densities and properties links upper and lower thermal tolerance thresholds and contributes to their unidirectional shift. The high thermal sensitivity of mitochondrial proton leakage may contribute to a rise in oxygen demand towards high temperature extremes. Some oxygen demand will also result from increased costs of ventilation and circulation in the warm and from the exponential in- 


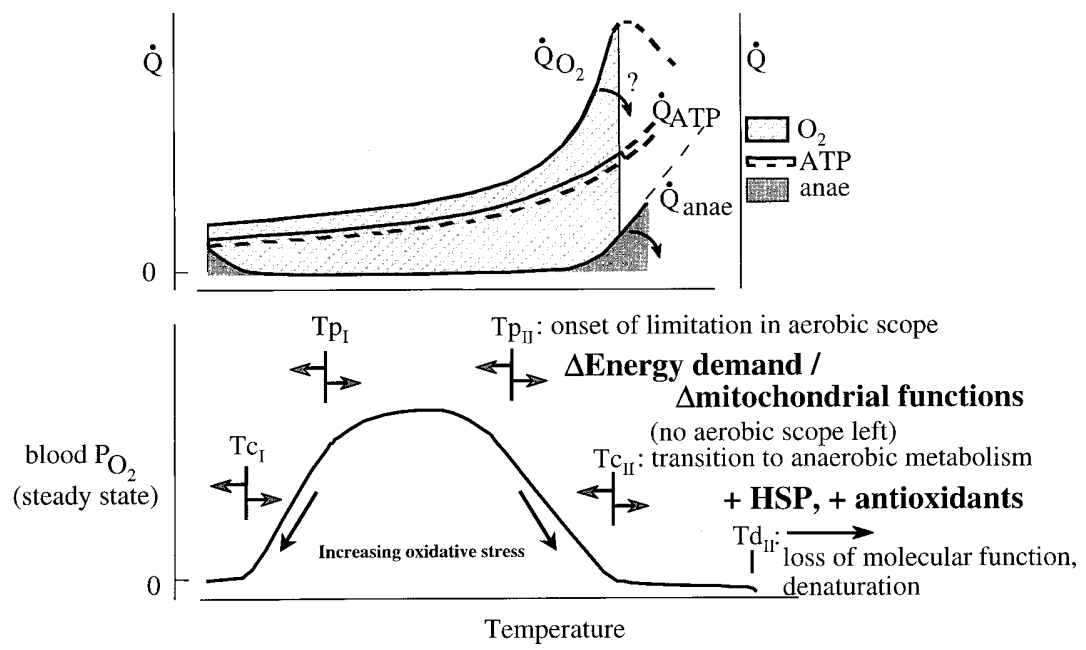

Fig. 6 Model of thermal tolerance thresholds in animals considering changes in metabolic heat production according to patterns of oxygen consumption $\left(Q_{2}\right)$ or anaerobic heat production $\left(Q_{\text {anae }}\right)$ as well as the discrepancy induced by mitochondrial proton leakage between total aerobic heat production and the respective quantity related to ATP turnover. The model is predominantly based on data for water breathers ( $T_{\mathrm{c}}$ critical, $T_{\mathrm{p}}$, pejus, $T_{\mathrm{d}}$ denaturation temperatures, cf. Fig. 1). A change in overall mitochondrial functional capacity contributes to a unidirectional shift in both upper and lower $T_{\mathrm{c}}$ and $T_{\mathrm{p}}$. Arrows illustrate the progressive rise in oxidative stress during hypoxia and the relative drop in oxygen demand as well as anaerobic heat production expected from a decrease in mitochondrial density in the warm. A shift in upper (and lower) denaturation temperatures may depend on the presence of heat shock proteins $(H S P)$ or antioxidants. A rise in mitochondrial capacity together with similar effects of HSP and antioxidants would cause a downward shift of threshold temperatures in the cold (not shown for $\mathrm{T}_{\mathrm{dI}}$ )

crease in cell membrane and epithelial permeability (Moseley et al. 1994), which requires energy for the compensation of dissipative ion movements.

Loss of protein function, neuromuscular failure, the heat shock response or oxidative stress may become detrimental later than oxygen limitation, reflecting more extreme denaturation temperatures $\left(T_{\mathrm{d}}\right.$ in Fig. 6, for review see Pörtner et al. 2000). At lower levels of complexity, each individual molecular or membrane function has been optimised with respect to ambient temperature such that $T_{\mathrm{d}}$ probably correlates with whole-animal tolerance thresholds, however, at temperatures beyond pejus or even critical values. For example, a shift in the thermal sensitivity of maximum respiration and phosphorylation in isolated mitochondria, a process at a lower level of complexity, may indicate functional disturbance. This shift correlates with habitat temperature but beyond the tolerance limits of the whole organism (Somero et al. 1998; Weinstein and Somero 1998), i.e. above $T_{\mathrm{c}}$ (Pörtner et al. 2000). In the whole organism, disintegration of "lower complexity" mechanisms may even be a consequence of oxygen deficiency when temperatures change beyond $T_{\mathrm{p}}$ or $T_{\mathrm{c}}$ (Fig. 6). Heat shock proteins (cf. Tomanek and Somero 2000) and antioxidants (cf. Abele et al. 1998) contribute to shift $T_{\mathrm{d}}$ to more extreme temperatures, thereby supporting short-term survival in extreme environments such as the intertidal zone. The same mechanisms may be effective in the cold. Owing to cause and effect relationships between the different levels of thermal sensitivity a hierarchy of thermal sensitivities results, where oxygen limitation is found at the highest level.

In the extreme cold, thermal tolerance is not only limited by insufficient oxygen uptake. For example, in polar areas only those fishes that have overcome these limits by the development of antifreeze proteins will thrive (for a review see DeVries 1988; Fletcher et al. 1998; Wöhrmann 1998). Similarly, supercooling points in insects correlate with geographical distribution (AddoBediako et al. 2000) since supercooling guarantees passive survival during winter cold. High levels of magnesium in the body fluids limit cold tolerance in marine crustaceans (Frederich et al. 2000a), thereby explaining why the group of reptant decapods is not found in polar areas with permanent subzero water temperatures (Arntz et al. 1994). Muscular relaxation by $\mathrm{Mg}^{2+}$ is enhanced in the cold, restricts ventilatory and circulatory capacities (Frederich et al. 2000b) and, in consequence, exacerbates the oxygen limitation of cold tolerance in this animal group. Amphipods, isopods and shrimp with low haemolymph $\mathrm{Mg}^{2+}$ levels occupy those niches in polar areas which in other oceans are usually dominated by benthic crabs. In terrestrial environments, the relationship between temperature and the physiological problems associated with dehydration will also be relevant.

From an ecological perspective, pejus rather than critical temperatures are likely to reflect the upper and lower temperature limits determining geographical distribution. In the future, this conclusion needs to be tested and quantified for both air and water breathing species in a latitudinal cline, in a collaborative effort between physiologists and ecologists. In this context, the hierarchy of pejus, critical and denaturation temperatures and the distances between these thresholds await quantification in many water breathers including fish. This is true even more so in air breathers, where an oxygen limitation of thermal tolerance still needs unequivocal verification for most groups. These investigations should also address the tradeoffs involved in thermal adaptation and the con- 
sequences for the success of species in thermally stable versus unstable environments.

Acknowledgements A contribution to the ELOISE Project: "Effects of climate induced temperature change on marine coastal fishes (CLICOFI)", funded by the European Union programme "Preserving the ecosystem", contract No. ENV4-CT97-0596. The author wishes to thank Dr. Franz Riemann for providing information on the thermal tolerance of nematodes. ELOISE publication No 218.

\section{References}

Abele D, Burlando B, Viarengo A, Pörtner HO (1998) Exposure to elevated temperatures and hydrogen peroxide elicits oxidative stress and antioxidant response in the Antarctic intertidal limpet Nacella concinna. Comp Biochem Physiol 120B:425-435

Abele D, Tesch C, Wencke P, Pörtner HO (2001) How does oxidative stress relate to thermal tolerance in the Antarctic bivalve Yoldia eightsi? Antarct Sci 13 (in press)

Addo-Bediako A, Chown SL, Gaston KJ (2000) Thermal tolerance, climatic variability and latitude. Proc R Soc Lond B 267:739-745

Ando M, Katagiri K, Yamomoto S, Asunama S, Usuda M, Kawahara I, Wakamutsu K (1994) Effect of hyperthermia in glutathione peroxidase and lipid peroxidative damage in liver. J Therm Biol 19:177-1285

Arntz WE, Brey T, Gallardo VA (1994) Antarctic zoobenthos. Oceanogr Mar Biol Annu Rev 32:241-304

Bennett AF (1978) Activity metabolism of the lower vertebrates. Annu Rev Physiol 400:447-469

Bhaumik G, Srivastava KK, Selvamurthy W, Purkayastha SS (1995) The role of free radicals in cold injuries. Int J Biometeorol 38:171-175

Branco LGS, Steiner AA (1999) Central thermoregulatory effects of lactate in the toad Bufo paracnemis. Comp Biochem Physiol A 122:457-461

Branco LGS, Pörtner HO, Wood SC (1993) Interaction between temperature and hypoxia in the alligator. Am J Physiol 265: R1339-R1343

Brand MD (1990) The contribution of the leak of protons across the mitochondrial inner membrane to standard metabolic rate. J Theor Biol 145:267-286

Brand MD, Chien L-F, Ainscow EK, Rolfe DFS, Rolfe RK (1994) The causes and functions of mitochondrial proton leak. Biochim Biophys Acta 1187:132-139

Bridges CR, Roux JM le, Aardt WJ van (1997) Ecophysiological adaptations to dry thermal environments measured in two unrestrained Naminian scorpions, Parabuthus villosus (Buthidae) and Opisthophthalmus flavescens (Scorpionidae). Physiol Zool 70:244-256

Brookes PS, Buckingham JA, Tenreiro AM, Hulbert AJ, Brand MD (1998) The proton permeability of the inner membrane of liver mitochondria from ectothermic and endothermic vertebrates and from obese rats: correlations with standard metabolic rate and phospholipid fatty acid composition. Comp Biochem Physiol 119B:325-334

Burdon RH (1987) Thermotolerance and the heat shock proteins. In: Bowler K, Fuller BJ (eds) Temperature and animal cells (Symposia of the Society for Experimental Biology 41) Company of Biologists, Cambridge, pp 269-283

Caputa M, Dokladny K, Kurowicka B (2000) Endotoxemia does not limit heat tolerance in rats: the role of plasma lipoproteins. Eur J Appl Physiol 82:142-150

Chown SL, Gaston KJ (1999) Exploring links between physiology and ecology at macro-scales: the role of respiratory metabolism in insects. Biol Rev 74:87-120

Chown SL, Merwe M van der, Smith VR (1997) The influence of habitat and altitude on oxygen uptake in sub-Antarctic weevils. Physiol Zool 70:116-124
Cossins AR, Bowler K (1987) Temperature biology of animals. Chapman and Hall, London

Dahlhoff EP, Rank NE (2000) Functional and physiological consequences of genetic variation at phosphoglucose isomerase: heat shock protein expression is related to enzyme genotype in a montane beetle. Proc Natl Acad Sci USA 10:10056-10061

Dahlhoff E, Somero GN (1991) Pressure and temperature adaptation of cytosolic malate dehydrogenases of shallow- and deepliving marine invertebrates: evidence for high body temperatures in hydrothermal vent animals. J Exp Biol 159:473487

Desbruyeres D, Chevaldonne P, Alayse A-M, Jollivet D, Lallier F, Jouin-Toulmond C, Zal F, Sarradin P-M, Cosson R, Caprais J-C, Arndt C, O'Brien J, Guezennec J, Hourdez S, Riso R, Gaill F, Laubier L, Toulmond A (1998) Biology and ecology of the "Pompeii worm" (Alvinella pompejana Desbruyeres and Laubier), a normal dweller of an extreme deep-sea environment: a synthesis of current knowledge and recent developments. Deep-Sea Res 45:383-422

DeVries AL (1988) The role of antifreeze glycopeptides and peptides in the freezing avoidance of Antarctic fishes. Comp Biochem Physiol 90B:611-621

De Wachter B, Sartoris F-J, Pörtner HO (1997) The anaerobic endproduct lactate has a behavioural and metabolic signalling function in the shore crab Carcinus maenas. J Exp Biol 200:1015-1024

Dijk PLM van, Hardewig I, Tesch C, Pörtner HO (1999) Physiological disturbances at critically high temperatures: a comparison between stenothermal Antarctic, and eurythermal temperate eelpouts (Zoarcidae). J Exp Biol 202:3611-3621

Dippner JW (1997) Recruitment success of different fish stocks in the North Sea in relation to climate variability. Dtsch Hydrogr Z 49:277-293

Dynesius M, Jansson R (2000) Evolutionary consequences of changes in species' geographical distributions driven by Milankovitch climate oscillations. Proc Natl Acad Sci USA 97:9115-9120

Elliott JM, Elliott JA (1995) The effect of the rate of temperature increase on the critical thermal maximum for parr of Atlantic salmon and brown trout. J Fish Biol 47:917-919

Farrell AP (1997) Effects of temperature on cardiovascular performance. In: Wood CM, McDonald DG (eds) Global warming: implications for freshwater and marine fish. Cambridge University Press, Cambridge, pp 135-158

Fletcher GL, Goddard SV, Davies PL, Gong Z, Ewart KV, Hew CL (1998) New insights into fish antifreeze proteins: physiological significance and molecular regulation. In: Pörtner HO, Playle R (eds) Cold ocean physiology. Cambridge University Press, Cambridge, pp 239-265

Frederich M, Pörtner HO (2000) Oxygen limitation of thermal tolerance defined by cardiac and ventilatory performance in the spider crab, Maja squinado. Am J Physiol 279:R1531-R1538

Frederich M, Sartoris FJ, Arntz W, Pörtner HO (2000a) Haemolymph magnesium regulation in decapod crustaceans: physiological correlates and ecological consequences in polar areas. J Exp Biol 203:1383-1393

Frederich M, De Wachter B, Sartoris FJ, Pörtner HO (2000b) Cold tolerance and the regulation of cardiac performance and hemolymph distribution in Maja squinado (Crustacea: Decapoda). Physiol Biochem Zool 73: 406-415

Fujita J (1999) Cold shock response in mammalian cells. J Mol Microbiol Biotechnol 1:243-255

Fuster JF, Pages T, Palacios L (1997) Effect of temperature on oxygen stores during aerobic diving in the freshwater turtle Mauremys caspica-leprosa. Physiol Zool 70:7-18

Guderley H (1998) Temperature and growth rates as modulators of the metabolic capacities of fish muscle. In: Pörtner HO, Playle $\mathrm{R}$ (eds) Cold ocean physiology. Cambridge, University Press, Cambridge, pp 58-87

Hardewig I, Peck LS, Pörtner HO (1999) Thermal sensitivity of mitochondrial function in the Antarctic Notothenioid, Lepidonotothen nudifrons. J Comp Physiol B 169:597-604 
Hazel JR (1995) Thermal adaptation in biological membranes: is homeoviscous adaptation the explanation? Annu Rev Physiol 57:19-42

Hoppeler H, Weibel ER (1998) Limits for oxygen and substrate transport in mammals. J Exp Biol 201:1051-1064

Hummel H, Sommer A, Bogaards R, Pörtner HO (1997) Variation in genetic traits of the lugworm Arenicola marina: temperature related expression of mitochondrial allozymes? Mar Ecol Prog Ser 159:189-195

Ivanov KP (2000) Physiological blocking of the mechanism of cold death: theoretical and experimental considerations. J Therm Biol 25:467-479

Ivany LC, Patterson WP, Lohmann KC (2000) Cooler winters as a possible cause of mass extinctions at the Eocene/Oligocene boundary. Nature 407:887-890

Jackson DC (1971) The effect of temperature on ventilation in the turtle Pseudemys scripta elegans. Respir Physiol 12:131-140

Johnston IA (1990) Cold adaptation in marine organisms. Philos Trans R Soc Lond B 326:655-667

Jourdan ML, Hoo-Paris R, Wang LCH (1989) Characterization of hypothermia in a non-hibernator: the rat. In: Malan A, Canguilhem B (eds) Living in the cold, vol II. Colloque INSERM/John Libbey Eurotext, Montrouge, France, pp 289296

Klyashtorin L (1997) Pacific salmon: climate-linked long-term stock fluctuations. PICES Press 5:2-34

Lahdes E (1995) Acute thermal tolerance of two Antarctic copepods, Calanoides acutus and Calanus propinquus. J Therm Biol 20:75-78

Lindstedt SL, McGlothlin T, Percy E, Pifer J (1998) Task-specific design of skeletal muscle: balancing muscle structural composition. Comp Biochem Physiol 120B:35-40

Moseley PL, Gapen C, Wallen ES, Walter ME, Peterson MW (1994) Thermal stress induces epithelial permeability. Am J Physiol 267:C425-C434

O'Brien CM, Fox CJ, Planque B, Casey J (2000) Climate variability and North Sea cod. Nature 404:142

Peck LS, Conway LZ (2000) The myth of metabolic cold adaptation: oxygen consumption in stenothermal Antarctic bivalves. In: Harper E, Taylor, JD, Crame JA (eds) Evolutionary biology of the Bivalvia. (Special Publication 177) Geological Society, London, pp 441-450

Pörtner HO, Zielinski S (1998) Environmental constraints and the physiology of performance in squids. In: Payne AIL, Lipinski MR, Clarke MR, Roeleveld MAC (eds) Cephalopod biodiversity, ecology and evolution. S Afr J Mar Sci 20:207-221

Pörtner HO, Branco LGS, Malvin GM, Wood SC (1994) A new function for lactate in the toad Bufo marinus. J Appl Physiol 76: $2405-2410$

Pörtner HO, Hardewig I, Sartoris FJ, Dijk PLM van (1998) Energetic aspects of cold adaptation: critical temperatures in metabolic, ionic and acid-base regulation? In: Pörtner HO, Playle R (eds) Cold ocean physiology. Cambridge University Press, Cambridge, pp 88-120

Pörtner HO, Peck L, Zielinski S, Conway LZ (1999a) Intracellular $\mathrm{pH}$ and energy metabolism in the highly stenothermal Antarctic bivalve Limopsis marionensis as a function of ambient temperature. Polar Biol 22:17-30

Pörtner HO, Hardewig I, Peck LS (1999b) Mitochondrial function and critical temperature in the Antarctic bivalve, Laternula elliptica. Comp Biochem Physiol 124A:179-189

Pörtner HO, Dijk PLM van, Hardewig I, Sommer A (2000) Levels of metabolic cold adaptation: tradeoffs in eurythermal and stenothermal ectotherms. In: Davison W, Howard Williams C (eds) Antarctic ecosystems: models for wider ecological understanding. Caxton Press, Christchurch, New Zealand, pp 109-122

Pörtner HO, Berdal B, Blust R, Brix O, Colosimo A, De Wachter B, Giuliani A, Johansen T, Fischer T, Knust R, Naevdal G, Nedenes A, Nyhammer G, Sartoris FJ, Serendero I, Sirabella P, Thorkildsen S, Zakhartsev M (2001) Climate effects on growth performance, fecundity and recruitment in marine fish: developing a hypothesis for cause and effect relationships in Atlantic cod (Gadus morhua) and common eelpout (Zoarces viviparus). Nearshore Coastal Oceanogr (in press)

Rifkind JM, Abugo O, Levy A, Monticone R, Heim J (1993) Formation of free radicals under hypoxia. In: Hochachka PW, Lutz PL, Sick T, Rosenthal M, Thillart G van den (eds) Surviving hypoxia: mechanisms of control and adaptation. CRC, Boca Raton, pp 509-525

Rolfe DFS, Brand MD (1996) Contribution of mitochondrial proton leak to skeletal muscle respiration and to standard metabolic rate. Am J Physiol 271:C1380-C1389

Roy K, Jablonski D, Valentine JW, Rosenberg G (1998) Marine latitudinal diversity gradients: tests of causal hypotheses. Proc Natl Acad Sci USA 95:3699-3702

Schmidt-Nielsen K (1997) Animal physiology: adaptation and environment, 5th edn. Cambridge University Press, Cambridge

Schwerdtfeger F (1977) Ökologie der Tiere: Autökologie. Verlag Paul Parey, Hamburg

Shelford VE (1931) Some concepts of bioecology. Ecology 12: $455-467$

Somero GN, Fields PA, Hofmann GE, Weinstein RB, Kawall H (1998) Cold adaptation and stenothermy in Antarctic notothenioid fishes: what has been gained and what has been lost? In: Di Prisco G, Pisano E, Clarke A (eds) Fishes of Antarctica: a biological overview. Springer, Berlin Heidelberg New York, pp 97-109

Sommer A, Pörtner HO (1999) Exposure of Arenicola marina (L.) to extreme temperatures: adaptive flexibility of a boreal and a subpolar population. Mar Ecol Prog Ser 181:215-226

Sommer A, Klein B, Pörtner HO (1997) Temperature induced anaerobiosis in two populations of the polychaete worm Arenicola marina (L.). J Comp Physiol 167B:25-35

Storelli C, Acierno R, Maffia M (1998) Membrane lipids and protein adaptations in Antarctic fish. In: Pörtner HO, Playle R (eds) Cold ocean physiology. Cambridge University Press, Cambridge, pp 166-189

St-Pierre J, Charest P-M, Guderley H (1998) Relative contribution of quantitative and qualitative changes in mitochondria to metabolic compensation during seasonal acclimatisation of rainbow trout Oncorhynchus mykiss. J Exp Biol 201:2961-2970

Tansey MR, Brock TD (1972) The upper temperature limit for eukaryotic organisms. Proc Natl Acad Sci USA 69:2426-2428

Taylor CR, Weibel ER (1981) Design of the mammalian respiratory system. I. Problem and strategy. Respir Physiol 44:1-10

Tomanek L, Somero GN (2000) Time course and magnitude of synthesis of heat-shock proteins in congeneric marine snails (genus Tegula) from different tidal heights. Physiol Biochem Zool 73:249-256

Urban HJ (1998) Upper temperature tolerance of two Antarctic molluscs (Laternula elliptica and Nacella concinna) from Potter Cove, King George Island, Antarctic Peninsula. Ber Polarforsch 299:230-236

Wehner R, Marsh AC, Wehner S (1992) Desert ants on a thermal tightrope. Nature 357:586-587

Weinstein RB, Somero GN (1998) Effects of temperature on mitochondrial function in the Antarctic fish Trematomus bernacchii. J Comp Physiol 168B:190-196

White FN, Somero G (1982) Acid-base regulation and phospholipid adaptations to temperature: time courses and physiological significance to modifying the milieu for protein function. Physiol Rev 62:40-90

Wieser W (1985) Developmental and metabolic constraints of the scope of activity in young rainbow trout (Salmo gairdneri). J Exp Biol 118:133-142

Wöhrmann APA (1998) Antifreeze glycopeptides and peptides in the freezing avoidance of Weddell Sea fishes: its relation to mode of life, depth distribution and evolution. In: Pörtner HO, Playle R (eds) Cold ocean physiology. Cambridge University Press, Cambridge, pp 266-295

Zielinski S, Pörtner HO (1996) Energy metabolism and ATP freeenergy change of the intertidal worm, Sipunculus nudus, below a critical temperature. J Comp Physiol 166B:492-500 